AKUNTABILITAS

Vol. VII, No. 2, Agustus 2014

P-ISSN: $1979-858 \mathrm{X}$

Halaman 132 - 145

\title{
PENGARUH AUDIT TENURE DAN LOWBALLING TERHADAP PEMBERIAN OPINI AUDIT
}

\author{
Eka Fitri Yanti \\ Yulianti \\ Amilin \\ UIN Syarif Hidayatullah Jakarta
}

\begin{abstract}
The main purpose of this study was to examine the influence of audit tenure and lowballing to the appropriation of audit opinion. Based on convenience sampling method. This study used a sample of 61 respondents who work as auditor in audit firm located in Jakarta and enrolled in Directory AP E KAP 2013 published by IAPI. This study used primary data with questionnaire. Auditor who participated in this research include partner, manager, supervisor, senior auditors and junior auditors who carry out work in the field of auditing The data was analyzed by multiple regression. The results indicates that the audit tenure didn't have an influence to the present of audit opinion. But lowballing had influenced to the present of audit opinion.
\end{abstract}

Keywords: Audit Tenure, Lowballing, Present of Audit Opinion

ABSTRAK: Tujuan utama dari penelitian ini adalah untuk menguji pengaruh kepemilikan audit dan lowballing terhadap pemberian opini audit. Penentuan sample berdasarkan metode convenience sampling. Penelitian ini menggunakan sampel 61 responden yang bekerja sebagai auditor di perusahaan audit yang berlokasi di Jakarta dan terdaftar dalam direktori AP \& KAP 2013 yang diterbitkan oleh IAPI. Penelitian ini menggunakan data primer dengan kuesioner. Auditor yang berpartisipasi dalam penelitian ini meliputi partner, manajer, supervisor, auditor senior dan auditor junior yang melaksanakan pekerjaan di bidang auditing. Data dianalisis dengan menggunakan regresi berganda. Hasil menunjukkan bahwa masa jabatan audit tidak memiliki pengaruh terhadap pemberian opini audit, sedangkan lowballing memiliki pengaruh terhadap pemberian opini audit.

Kata kunci: Audit Tenure, Lowballing, Opini Audit

Draft pertama: 26 Maret 2014; Revisi: 18 April 2014; Diterima: 23 Mei 2014

*Penulis dapat dikontak melalui: ekafitriyanti93@gmail.com 


\section{PENDAHULUAN}

Laporan keuangan menyediakan berbagai informasi yang diperlukan sebagai sarana pengambilan keputusan baik oleh pihak internal maupun pihak eksternal perusahaan. Menurut FASB, dua karakteristik terpenting yang harus ada dalam laporan keuangan adalah relevan (relevance) dan dapat diandalkan (reliable). Kedua karakteristik tersebut sangatlah sulit untuk diukur, sehingga para pemakai informasi membutuhkan jasa pihak ketiga yaitu auditor independen untuk memberi jaminan bahwa laporan keuangan tersebut relevan dan dapat diandalkan, sehingga dapat meningkatkan kepercayaan semua pihak yang berkepentingan dengan perusahaan tersebut (Singgih dan Bawono, 2010).

Auditor independen mempunyai peran untuk menengahi perbedaan kepentingan yang terjadi tersebut. Auditor harus mampu menghasilkan opini yang berkualitas, sehingga opini atas kewajaran laporan keuangan tersebut dapat menjamin kehandalan informasi yang terdapat dalam laporan keuangan perusahaan. Auditor eksternal selain bertanggung jawab kepada kepentingan klien juga harus bertanggung jawab atas hasil kerja yang dipublikasikan kepada pihak-pihak diluar entitas, yaitu berupa laporan audit. Dengan adanya laporan audit, pemegang saham dan pengguna laporan keuangan lainnya dapat menghindari kesalahan dalam pembuatan keputusan.

Kasus yang terjadi dalam dunia bisnis terkait kegagalan auditor dalam mendeteksi kecurangan terbukti dengan adanya skandal Olympus Corp., produsen kamera asal Jepang. Olympus Corp., mengaku telah menyembunyikan kerugian investasi di perusahaan sekuritas selama puluhan tahun atau sejak era 1980-an. Kasus ini mencuat setelah pemecatan CEO Olympus Michael Woodford. Woodford meminta perusahaan menjelaskan tentang transaksi yang mecurigakan sebesar 1,3 miliar dollar AS. Setelah dilakukan penyelidikan internal perusahaan menemukan sejumlah dana yang mencurigakan terkait akuisisi dengan Gyrus, produsen peralatan medis asal Inggris (Aliya, 2011). Financial Times bulan Oktober 2011 melaporkan ada yang janggal dengan opini KPMG terkait pembukuan Olympus. Tidak ada perselisihan antara KPMG dan Olympus yang diungkap ke publik, namun kemudian terkuak dalam artikel 4 November 2011 di Daily Telegraph. Begitu pula dengan opini Ernst \& Young yang tidak mengungkap terjadi masalah (Rakhmatullah, 2011). Berdasarkan temuan-temuan tersebut dapat dilihat bahwa tidak hanya Arthur Andersen, melainkan KPMG dan Ernst \& Young pun masih dapat melakukan kesalahan memberikan opini dalam laporan audit. Karena kegagalan dalam mendeteksi maupun mengungkapkan kecurangan laporan keuangan mereka.

Hasil akhir dari proses audit laporan keuangan perusahaan adalah berupa pemberian opini audit. Pemberian opini audit yang tepat dan sesuai dengan kriteria-kriteria yang ditetapkan dalam Standar Profesional Akuntan Publik (SPAP) sangat penting agar hasil audit tidak menyesatkan para pengguna yang berkepentingan dalam pengambilan keputusan, oleh karena itu audit harus dilakukan dengan sebaik-baiknya.

Lowballing mempunyai dampak adanya peningkatan pendapatan oleh KAP pada masa perikatan berikutnya oleh klien. KAP di masa datang, tentu mempunyai hubungan erat dengan tenure KAP. Kondisi tenure yang panjang diduga akan menciptakan masalah eskalasi komitmen yang terkait dengan tindakan lowballing untuk menghasilkan pendapatan lain pada masa mendatang (Moore, Tetlock, Tanlu and Bazerman, 2006 dalam Giri, 2010).

Semakin lamanya tenure yang dimiliki oleh seorang auditor eksternal, berarti meningkatkan kompetensi auditor karena auditor lebih mengenal seluk beluk bisnis klien, sehingga proses audit menjadi lebih efisien. Disisi lain audit tenure mungkin merusak independensi auditor sebagai masa yang panjang memupuk kedekatan antara manajemen dan auditor (Junaidi, Hartono, Suwardi dan Muharjo, 2013).

Penelitian audit tenure terhadap opini audit telah dilakukan diantaranya oleh Arsianto (2013) yang membuktikan bahwa audit tenure berpengaruh terhadap pemberian 
opini audit going concern. Penelitian ini sejalan dengan yang dilakukan oleh Shafie et. al., (2009) dalam Saputri (2012) yang menyatakan bahwa perusahaan yang tidak pernah mengganti auditor sejak listed di Bursa Malaysia, terdapat tendensi menerima opini unqualified lebih tinggi meskipun perusahaan tersebut mengalami masalah keuangan.

Penelitian lowballing terhadap independensi sudah dilakukan oleh DeAngelo (1981). Dalam penelitiannya yang berjudul Auditor Independence, Low Balling and Disclosure Regulation, menghasilkan kesimpulan bahwa lowballing tidak berpengaruh terhadap independensi auditor. Fatemi (2013) juga melakukan penelitian yang sama dan hasilnya lowballing berpengaruh terhadap independensi auditor. Serupa dengan penelitian yang dilakukan oleh Elitzur and Falk (1996). Pembedanya berupa variabel dependen yang digunakan berupa jasa audit. Penelitiannya membuktikan bahwa lowballing berpengaruh terhadap jasa audit. Sedangkan peneliti menggunakan variabel pemberian opini audit sebagai variabel dependen yang menjadi pembeda dengan penelitian-penelitian sebelumnya. Penelitian lowballing terhadap pemberian opini audit adalah pengembangan dari argumen Dye (1991) dalam Giri (2010) yang menyatakan bahwa lowballing mendorong auditor membuat opini yang memberi keuntungan bagi klien pada awal perioda dan kondisi ini digunakan auditor untuk memperoleh pendapatan dengan harapan klien akan melakukan perikatan pada perioda selanjutnya.

Maksud dari penelitian ini adalah untuk mengetahui pengaruh dari Audit Tenure dan Lowballing terhadap pemberian opini audit.

\section{KERANGKA TEORI DAN PENGEMBANGAN HIPOTESIS Teori Keagenan}

Jensen dan Meckling (1976) mendefinisikan hubungan keagenan sebagai suatu kontrak dimana satu orang atau lebih (principal) meminta pihak lainnya (agent) untuk melaksanakan sejumlah pekerjaan atas nama principal yang melibatkan pendelegasian beberapa wewenang pembuatan keputusan kepada agent. Jika kedua pihak yang terlibat dalam kontrak tersebut berusaha untuk memaksimalkan utilitas mereka maka ada kemungkinan bahwa agent tidak akan selalu bertindak untuk kepentingan terbaik prinsipal. Namun, Agent sebagai pihak yang menghasilkan laporan keuangan memiliki keinginan untuk mengoptimalisasi kepentingannya, sehingga dimungkinkan agent melakukan manipulasi data atas kondisi perusahaan (Sari dan Rahardja, 2012).

\section{Pemberian Opini Audit}

Setelah selesai melakukan pemeriksaan/audit alat formal, auditor independen mengkomunikasikan kesimpulan yang diperoleh mengenai laporan keuangan auditan berupa laporan audit. Opini audit menurut Standar Profesional Akuntan Publik terdiri atas 5 jenis yaitu Pendapat wajar tanpa pengecualian, Pendapat wajar tanpa pengecualian dengan bahasa penjelasan ditambahkan dalam laporan auditor bentuk baku, Pendapat wajar dengan pengecualian, Pendapat tidak wajar dan Tidak memberikan pendapat.

\section{Audit Tenure dan Pemberian Opini Audit}

Audit tenure adalah lamanya waktu auditor melakukan pekerjaan audit secara berturut-turut terhadap suatu klien yang diukur berdasarkan jumlah tahun. Audit tenure yang panjang dapat meningkatkan kompetensi auditor karena auditor lebih mengenal seluk beluk bisnis klien, sehingga proses audit menjadi lebih efisien. Disisi lain audit tenure mungkin merusak independensi auditor sebagai masa yang panjang memupuk kedekatan antara manajemen dan auditor (Junaidi, dkk., 2013).

Raharja (2007) menyatakan bahwa faktor yang terkait antara hubungan profesi akuntan dengan dunia bisnis yaitu sumber pendapatan akuntan hampir seluruh pendapatannya berasal dari perusahaan bisnis. Klien yang menghidupi kantor akuntan 
publik. Faktor yang terkait dengan dekatnya hubungan profesi akuntan dengan dunia bisnis dapat dirinci sebagai berikut:

a. Ketergantungan finansial.

b. Adanya hubungan konfidensial antara auditor dan klien. Hubungan yang menjadi jaminan profesi ini seolah-olah auditor akan menutupi keburukan klien. Dan Tekanan yang kuat untuk melayani manajemen.

Independensi auditor dapat hilang dikarenakan auditor terlibat dalam hubungan pribadi dengan klien, hal ini dapat mempengaruhi sikap mental dan opini mereka. Penelitian yang dilakukan oleh Shafie et. al., (2009) dalam Saputri (2012) yang menyatakan bahwa perusahaan yang tidak pernah mengganti auditor sejak listed di Bursa Malaysia, terdapat tendensi menerima opini unqualified lebih tinggi meskipun perusahaan tersebut mengalami masalah keuangan.

Namun, disisi lain seorang auditor harus terbiasa (familiar) terhadap kliennya. Karena dengan terbiasa maka auditor dapat memahami klien dengan cukup baik guna perencanaan dan melakukan proses audit yang efektif dan efisien (AICPA Professional Standars, $A U$ 311). Menurut Bazerman et. al., (2002) peraturan tersebut menimbulkan konflik yang terjadi antara lain:

a. kebutuhan auditor untuk menjadi lebih familiar dengan klien guna melakukan proses audit yang tepat, sesuai dan lebih cepat;

b. ancaman terhadap objektifitas auditor dari familiaritasnya klien, yang mengarahkan pada kritik yang menyatakan bahwa tidaklah mungkin untuk mengharapkan auditor untuk melakukan penilaian yang bersifat objektif dan tidak bias.

\section{Lowballing dan Pemberian Opini Audit}

Lowballing adalah penawaran fee yang lebih rendah oleh auditor yang baru tanpa mengharapkan banyak manfaat dalam tahun pertama penugasan audit namun, auditor mengharapkan fee yang tinggi pada tahun berikutnya. Lowballing mengacu kepada diskon yang diberikan pada saat penugasan pertama oleh auditor eksternal ketika berpotensi untuk melakukan perikatan dalam jangka waktu yang lama dengan perusahaan klien (Lee dan Gu, 1998).

Persaingan antar KAP semakin besar karena KAP semakin bertambah banyak, sedangkan pertumbuhan perusahaan tidak sebanding dengan pertumbuhan KAP. Salah satu cara yang dilakukan KAP untuk menghadapi persaingan tersebut dengan melakukan penurunan fee. Kondisi tersebut memberikan indikasi bahwa penetapan audit fee dilakukan secara subjektif, artinya ditentukan oleh salah satu atau atas dasar kekuatan tawar menawar antara auditor dan klien (Suharli dan Nurlaelah, 2008).

Lowballing ditandai dengan struktur harga awal kurang dari total biaya dan dapat dapat meningkat sesuai dengan audit tenure. Dengan demikian klien akan bertahan setelah situasi berubah dengan asumsi klien akan membayar lebih mahal pada periode selanjutnya (Cialdinit, R. B., Capcioppo, J. T., Basset, R. \& Miller, 1978 dalam Jonasson and Tungel, 2012).

Fatemi (2013) mengamati bahwa ketika ada lowballing maka manajer akan menerima perikatan dengan KAP dengan harapan bahwa auditor akan mengungkapkan nilai asset yang lebih tinggi sehingga dipercaya oleh investor. Lowballing mendorong auditor membuat opini yang memberi keuntungan bagi klien pada awal periode dan kondisi ini digunakan auditor untuk memperoleh pendapatan dengan harapan klien akan melakukan perikatan audit pada periode selanjutnya (Dye, 1991 dalam Giri, 2010).

Berdasarkan kerangka teoritis dan penelitian terdahulu, maka dirumuskan hipotesis penelitian sebagai berikut:

$\mathrm{H}_{1}$ : Audit tenure berpengaruh terhadap pemberian opini audit.

$\mathrm{H}_{2:} \quad$ Lowballing berpengaruh terhadap pemberian opini audit. 


\section{METODE PENELITIAN}

Variabel dalam penelitian ini meliputi Audit Tenure, Lowballing sebagai variable independen, sedangkan pemberian opini audit menjadi variable dependen. Populasi dalam penelitian ini adalah auditor yang bekerja di Kantor Akuntan Publik yang berada di wilayah Jakarta. Teknik pengambilan sampel yang digunakan dalam penelitian ini adalah metode convenience sampling yaitu istilah umum yang mencakup variasi luasnya prosedur pemilihan responden dimana unit sampel yang ditarik mudah dihubungi, tidak menyusahkan, mudah untuk mengukur dan bersifat kooperatif (Hamid, 2012:28).

\section{HASIL DAN PEMBAHASAN}

Penelitian ini dilakukan terhadap auditor eksternal yang bekerja di Kantor Akuntan Publik (KAP) yang berada di wilayah Jakarta dan terdaftar dalam Directory Kantor Akuntan Publik 2013 yang diterbitkan oleh Institut Akuntan Publik Indonesia (IAPI). Auditor yang berpartisipasi dalam penelitian ini meliputi partner, manajer, supervisor, auditor senior dan auditor junior yang melaksanakan pekerjaan di bidang auditing. Pengumpulan data dilaksanakan melalui penyebaran kuesioner penelitian secara langsung seperti dengan cara mendatangi responden.

Peneliti mengambil sampel sebanyak 18 KAP dari keseluruhan KAP yang berada di wilayah Jakarta, yaitu 9 KAP di Jakarta Selatan, 2 KAP di Jakarta Pusat, 2 KAP di Jakarta Utara, 2 KAP berada di Jakarta Timur dan 3 KAP berada di Jakarta Barat. Kuesioner yang disebarkan berjumlah 125 buah dan jumlah kuesioner yang kembali adalah sebanyak 111 buah kuesioner atau 88,8\%. Kuesioner yang tidak kembali sebanyak 14 buah atau 11,2\%, hal ini mungkin dikarenakan waktu penyebaran kuesioner yang kurang tepat. Kuesioner yang dapat diolah berjumlah 61 buah atau 48,8\%, sedangkan kuesioner yang tidak dapat diolah karena tidak memenuhi kriteria sebagai sampel dan tidak diisi secara lengkap oleh responden sebanyak 50 buah atau 40\%. Tabel 1 di bawah ini menunjukkan karakteristik dari responden sebagai berikut:

Tabel 1. Karakteristik Profil Responden

\begin{tabular}{|c|c|c|c|}
\hline No. & Karakteristik & Jumlah & Presentase \\
\hline 1. & Jenis Kelamin & & \\
\hline & a. Laki-laki & 31 & $50,8 \%$ \\
\hline & b. Perempuan & 30 & $49,2 \%$ \\
\hline 2. & Posisi Terakhir & & \\
\hline & a. Partner & 2 & $3 \cdot 3 \%$ \\
\hline & b. Manajer & 3 & $4.9 \%$ \\
\hline & c. Supervisor & 6 & $9.8 \%$ \\
\hline & d. Auditor Senior & 29 & $47 \cdot 5 \%$ \\
\hline & e. Auditor Junior & 21 & $34.4 \%$ \\
\hline 3. & Pendidikan Terakhir & & \\
\hline & a. S2 & 3 & $4,9 \%$ \\
\hline & b. $S_{1}$ & 47 & $77 \%$ \\
\hline & c. $\mathrm{D}_{3}$ & 11 & $18 \%$ \\
\hline 4. & Usia & & \\
\hline & a. 21-25 & 15 & $24,6 \%$ \\
\hline & b. $26-30$ & 22 & $36,1 \%$ \\
\hline & c. $31-35$ & 13 & $21,3 \%$ \\
\hline & d. $36-40$ & 9 & $14,8 \%$ \\
\hline & e. $46-50$ & 2 & $3,3 \%$ \\
\hline 5. & Pengalaman Kerja & & \\
\hline
\end{tabular}




\begin{tabular}{|l|l|c|c|}
\hline a. $<5$ tahun & 25 & $41,0 \%$ \\
\hline & b. 5-10 tahun & 24 & $39,3 \%$ \\
\hline c. > 10 tahun & 12 & $19,7 \%$ \\
\hline Total & 61 & 61 \\
\hline
\end{tabular}

Sumber: Data primer yang diolah

Berdasarkan tabel 1, dapat dilihat bahwa sekitar 31 orang atau sebesar 50,8\% responden didominasi oleh jenis kelamin laki-laki dengan jumlah 31 orang atau sebesar 50,8\% dan sisanya sebanyak 30 orang atau sebesar $49,2 \%$ responden berjenis kelamin perempuan. Hal ini dikarenakan profesi auditor yang menuntut untuk memerlukan waktu yang lebih banyak dan tenaga yang lebih besar dalam pekerjaannya sehingga responden dalam penelitian ini didominasi oleh pria.

Berdasarkan tabel 1 di atas, diperoleh informasi bahwa mayoritas responden sebanyak 29 orang atau sebesar $47,5 \%$ menduduki posisi sebagai auditor senior. Responden yang menduduki posisi auditor junior sebanyak 21 orang atau sebesar 34,4\%. Responden yang menduduki posisi supervisor sebanyak 6 orang atau sebesar 9,8\%. Responden yang menduduki posisi manajer sebanyak 3 orang atau sebesar 4,9\%. Sedangkan, responden yang menduduki jabatan sebagai partner sebanyak 2 orang atau 3,3\%. Hal tersebut mungkin dikarenakan semakin tinggi jabatan seorang auditor di kantor akuntan publik, maka semakin tinggi pula tingkat kesibukannya.

Berdasarkan tabel 1 di atas, dapat diketahui bahwa sebanyak 3 responden atau sebesar 4,9\% berpendidikan terakhir Strata Dua (S2). Sebanyak 47 responden atau sebesar 77,0\% berpendidikan terakhir Strata Satu (S1). Sisanya sebanyak 11 orang atau sebesar 18,o\% berpendidikan terakhir Diploma Tiga $\left(\mathrm{D}_{3}\right)$. Berdasarkan hal tersebut, maka dapat disimpulkan bahwa responden terbanyak adalah responden dengan tingkat pendidikan terakhir S1, hal ini diduga karena di Indonesia pada umumnya standar pendidikan untuk direkrut menjadi auditor eksternal minimal Strata Satu (S1).

Berdasarkan tabel 1 di atas, menunjukkan responden yang bekerja pada kantor akuntan publik sebanyak 22 orang atau sebesar 36,1\% responden berusia 26 hingga 30 tahun, sebanyak 15 orang atau sebesar $24,6 \%$ responden berusia 21 hingga 25 tahun, sebanyak 13 orang atau sebesar $21,3 \%$ berusia 31 hingga 35 tahun, sebanyak 9 orang atau sebesar $14,8 \%$ berusia 36 hingga 40 tahun dan sisanya sebanyak 2 orang atau sebesar $3,3 \%$ berusia 46-50 tahun. Berdasarkan hal tersebut, maka dapat disimpulkan bahwa mayoritas responden yang bekerja pada kantor akuntan publik berusia 26 hingga 30 tahun sebesar $36,1 \%$ atau sebanyak 22 orang. Hal ini mungkin dikarenakan responden penelitian ini didominasi oleh auditor junior dan senior, sehingga usia responden dalam penelitian ini mayoritas relatif muda.

Berdasarkan tabel 1 di atas, dapat diketahui bahwa sebesar 41,0\% atau sebanyak 25 responden memiliki pengalaman bekerja kurang dari 5 tahun, sebesar $39,3 \%$ atau sebanyak 24 responden memiliki pengalaman bekerja 5 sampai 10 tahun dan sisanya sebanyak 12 responden atau sebesar $19,7 \%$ responden memiliki pengalaman bekerja lebih dari o tahun.

Statistik deskriptif memberikan gambaran atau deskripsi suatu data yang dilihat dari nilai rata-rata (mean), standar deviasi, varian, maksimum dan minimum (Ghozali, 2011:19).

Sesuai dengan permsalahan dan perumusan model yang telah dikemukakan, serta kepentingan pengujian hipotesis, maka teknik analisis dalam penelitian ini selanjutnay dilakukan dengan menggunakan analisis regresi linear berganda, terlebih dahulu dilakukan pengujian asumsi klasik yang terdiri dari uji normalitas, uji multikolinearitas, uji heterokedasitas, dan uji autokorelasi. 


\section{Uji Normalitas}

Uji normalitas bertujuan untuk menguji apakah dalam model regresi, variabel independen dan variabel dependen keduanya mempunyai distribusi normal atau mendekati normal (Ghozali, 2011:16o). Dalam penelitian ini, uji normalitas menggunakan Normal Probability Plot (P-P Plot). Suatu variabel dikatakan normal jika gambar distribusi dengan titik-titik data yang menyebar di sekitar garis diagonal dan penyebaran titik-titik data searah mengikuti garis diagonal (Ghozali, 2011:163). Pengujian dalam penelitian ini juga menggunakan uji One Sample Kolmogorov Smirnov yang memiliki kriteria untuk normalitas dipenuhi jika probabilitas signifikansi lebih besar dari o,05 (Ghozali, 2011:34).

Tabel 2. Tabel Normalitas

One-Sample Kolmogorov-Smirnov Test

\begin{tabular}{|ll|l|}
\hline & & $\begin{array}{l}\text { Unstandardized } \\
\text { Residual }\end{array}$ \\
\hline $\mathrm{N}$ & Mean & 58 \\
Normal Parameters ${ }^{\mathrm{a}, \mathrm{b}}$ & .0oooooo \\
& Std. Deviation & 3.10743548 \\
& Absolute & .123 \\
Most Extreme Differences & Positive & .084 \\
& Negative & -.123 \\
Kolmogorov-Smirnov Z & & .936 \\
Asymp. Sig. (2-tailed) & & .345 \\
\hline
\end{tabular}

a. Test distribution is Normal.

b. Calculated from data.

Sumber: Data primer yang diolah

Berdasarkan tabel 2 diatas yaitu dengan menggunakan Uji Kolmogorov-Smirnov (KS) pada alpha sebesar 5\% berarti data normal. Dari tabel 1 di atas terlihat bahwa nilai Kolmogorov-Smirnov sebesar 0,345 dengan nilai signifikansi diatas 0,05 yang berarti nilai residual terdistribusi secara normal.

\section{Hasil Uji Multikolonieritas}

Uji multikolonieritas bertujuan untuk menguji apakah model regresi ditemukan adanya korelasi antar variabel independen. Model regresi yang baik seharusnya tidak terjadi korelasi diantara variabel independen (Ghozali, 2011:105). Deteksi ada atau tidaknya multikolonieritas dalam model regresi adalah dilihat dari besaran VIF (Variance Inflation Factor) dan tolerance (TOL). Regresi bebas dari masalah multikolonieritas jika nilai VIF $<10$ dan nilai TOL > 0,1 (Ghozali, 2011:106).

Tabel 3. Hasil Uji Multikolinieritas

\begin{tabular}{|c|c|c|c|c|c|c|c|}
\hline \multirow{2}{*}{ Model } & \multicolumn{2}{|c|}{$\begin{array}{l}\text { Unstandardized } \\
\text { Coefficients }\end{array}$} & \multirow{2}{*}{$\begin{array}{l}\text { Standardized } \\
\text { Coefficients } \\
\text { Beta }\end{array}$} & \multirow{2}{*}{ TT } & \multirow{2}{*}{ Sig. } & \multicolumn{2}{|c|}{$\begin{array}{l}\text { Collinearity } \\
\text { Statistics }\end{array}$} \\
\hline & B & $\begin{array}{l}\text { Std. } \\
\text { Error }\end{array}$ & & & & Tolerance & VIF \\
\hline $\begin{array}{l}\text { (Constant) } \\
1 \text { TAT } \\
\text { TLB }\end{array}$ & $\begin{array}{l}13.761 \\
.158 \\
.510\end{array}$ & $\begin{array}{l}3.954 \\
.082 \\
.121\end{array}$ & $\begin{array}{l}.214 \\
.474\end{array}$ & $\begin{array}{l}3.480 \\
1.913 \\
4.228\end{array}$ & $\begin{array}{l}.001 \\
.061 \\
.000\end{array}$ & $\begin{array}{l}1.000 \\
1.000\end{array}$ & $\begin{array}{l}1.000 \\
1.000\end{array}$ \\
\hline
\end{tabular}

a. Dependent Variable: TOP 
Dari tabel 3 di atas, terlihat bahwa nilai tolerance menunjukkan angka 1,ooo dan nilai variance inflation factor (VIF) menunjukkan angka 1,0oo untuk setiap variabel, yang ditunjukkan dengan nilai tolerance untuk audit tenure 1,00o dan VIF nya 1,0oo, lowballing dengan nilai tolerance 1,ooo dan VIF nya 1,ooo. Dengan demikian, dapat disimpulkan bahwa model regressi tidak terdapat multikolonieritas dan dapat digunakan dalam penelitian ini.

\section{Hasil Uji Heteroskedastisitas}

Uji heteroskedestisitas bertujuan menguji apakah dalam model regresi terjadi ketidaksamaan varians dari residual satu pengamatan ke pengamatan yang lain. Jika varians dari residual satu pengamatan ke pengamaan yang lain tetap maka disebut homoskedastisitas, jika berbeda disebut heteroskedastisitas. Model regresi yang baik adalah homoskedastisitas (Ghozali, 2011:139).

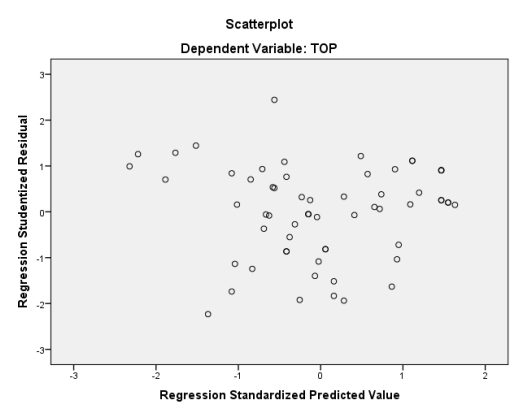

Gambar 1

Uji Heteroskedastisitas

Berdasarkan gambar di atas grafik scatterplot menunjukkan bahwa data tersebar di atas dan di bawah angka o (nol) pada sumbu Y dan tidak terdapat suatu pola yang jelas pada penyebaran data tersebut. Hal ini berarti tidak terjadi heteroskedastisitas pada model persamaan regresi, sehingga model regresi layak digunakan untuk memprediksi pemberian opini audit berdasarkan variabel yang mempengaruhinya, yaitu audit tenure dan lowballing.

\section{Uji Hipotesis}

Pengujian hipotesis dalam penelitian ini menggunakan regresi linear berganda, analisis ini dimaksudkan untuk mengetahui pengaruh variable-variabel bebas (independen) terhadap variable terikat atau yang dipengaruhi (dependen), baik secara parsial maupun simultan.

\section{Uji - t}

Pengujian regresi secara parsial (uji t) berguna untuk menguji pengaruh dari masing-masing variabel independen secara parsial terhadap variabel dependen.

Tabel 4. Hasil Uji Statistik t Variabel $X_{1}, X_{2}$ dan Y

Coefficients ${ }^{\mathrm{a}}$

\begin{tabular}{|l|l|l|l|l|l|}
\hline \multirow{2}{*}{ Model } & \multicolumn{2}{|l|}{$\begin{array}{l}\text { Unstandardized } \\
\text { Coefficients }\end{array}$} & $\begin{array}{l}\text { Standardized } \\
\text { Coefficients }\end{array}$ & \multirow{2}{*}{ T } & \multirow{2}{*}{ Sig. } \\
\cline { 2 - 4 } & B & Std. Error & Beta & & \\
\hline \multirow{2}{*}{$\begin{array}{l}\text { (Constant) } \\
\text { TAT }\end{array}$} & 13.761 & 3.954 & & 3.480 & .001 \\
TLB & .158 & .082 & .214 & .913 & .061 \\
\hline
\end{tabular}

a. Dependent Variable: TOP 
Berdasarkan hasil uji regresi t pada tabel 4 menunjukkan hasil uji koefisien regresi linear berganda menunjukkan bahwa variabel audit tenure mempunyai tingkat signifikansi (p) sebesar 0,061 lebih besar dari $\alpha .=5 \%$. Hal ini berarti menolak $H_{1}$ bahwa audit tenure tidak berpengaruh terhadap pemberian opini.

Hasil penelitian ini memberikan bukti empiris bahwa audit tenure yang lama tidak bisa mempengaruhi independensi auditor. Auditor akan tetap memberikan opini audit atas kesangsian laporan keuangan sesuai dengan Standar Akuntansi Keuangan di Indonesia. Hasil Kep-310/BL/2008 Peraturan Nomor VIII.A.2 juga menjelaskan tentang indepedensi akuntan yang memberikan jasa audit di pasar modal sehingga akuntan yang memberikan jasa audit di pasar modal akan berusaha untuk mematuhi peraturan yang telah ditetapkan oleh Bapepam tersebut. Di dalam peraturan tersebut juga dijelaskan bahwa auditor eksternal dalam memberikan jasa professional, khususnya dalam memberikan opini, auditor eksternal wajib senantiasa mempertahankan sikap independen. Hasil penelitian yang dilakukan oleh Sinason et. al., (2001) dengan responden penelitian adalah Kantor Akuntan Publik Big Six dan non Big Six, menyatakan bahwa masa audit yang lama tidak berpengaruh terhadap opini wajar tanpa pengecualian.

Audit tenure yang panjang tidak mempengaruhi pemberian opini audit yang didapatkan oleh klien. Karena semakin panjang audit tenure maka auditor akan lebih mengenal seluk beluk bisnis klien sehingga proses audit lebih efisien. Auditor akan tetap mempertahankan kualitas audit yang dimilikinya, yaitu dengan mempertahankan independensinya dengan tetap melaporkan apabila terdapat informasi yang menyesatkan dari klien dan tetap mengeluarkan opini audit yang sesuai dengan keadaan yang sebenarnya tanpa memperdulikan kehilangan fee audit yang diterima di masa mendatang karena kehilangan klien tersebut.

Tetapi penelitian ini tidak sejalan dengan penelitian yang dilakukan oleh Shafie et. al., (2009) dalam Saputri (2012) yang menyatakan bahwa perusahaan yang tidak pernah mengganti auditor sejak listed di Bursa Malaysia, terdapat tendensi menerima opini unqualified lebih tinggi meskipun perusahaan tersebut mengalami masalah keuangan.

Berdasarkan hasil uji regresi t pada tabel 4 menunjukkan hasil uji koefisien regresi linier berganda menunjukkan bahwa variabel lowballing mempunyai tingkat signifikansi sebesar o,ooo. Hal ini berarti menerima $\mathrm{H}_{2}$ sehingga dapat dikatakan bahwa lowballing berpengaruh secara signifikan terhadap pemberian opini audit karena tingkat signifikansinya lebih kecil dari o,05.

Hasil penelitian ini memberikan bukti empiris bahwa lowballing pada awal masa penugasan audit bisa mempengaruhi opini yang diberikan oleh auditor. Lowballing terjadi untuk persaingan dalam hal mendapatkan klien. Sikap auditor yang tidak independen akan mempengaruhi cara berpikirnya dan menyetujui tindakan klien yang keliru. Pemikiran auditor yang menginginkan terjadinya masa perikatan pada periode selanjutnya, disebabkan auditor memandang klien sebagai sumber pendapatan yang akan berdampak pada pemberian opini yang dilakukan oleh auditor.

Audit fee yang kecil kemungkinan dapat pula mendorong akuntan publik kurang independen dalam memberikan opini atas laporan keuangan klien karena waktu dan biaya yang terbatas (Supriyono, 1988:66 dalam Wati dan Subroto, 2003). Hal ini mendukung pernyataan yang disebutkan oleh Dye (1991) dalam Giri (2010) bahwa lowballing mendorong auditor membuat opini yang memberi keuntungan bagi klien pada awal perioda dan kondisi ini digunakan auditor untuk memperoleh pendapatan dengan harapan klien akan melakukan perikatan audit pada periode selanjutnya. 


\section{Uji Signifikasi Simultan (Uji Statistik F)}

Uji statistik F dilakukan untuk mengetahui pengaruh semua variabel independen yang dimasukkan ke dalam variabel model regresi secara bersama-sama terhadap variabel dependen.

Tabel 5 Hasil Uji F ANOVA ${ }^{a}$

\begin{tabular}{|l|l|l|l|l|l|}
\hline Model & $\begin{array}{l}\text { Sum of } \\
\text { Squares }\end{array}$ & Df & Mean Square & F & Sig. \\
\hline \multirow{2}{*}{$\begin{array}{l}\text { Regression } \\
1\end{array} \quad$ Residual } & 215.986 & 2 & 107.993 & 10.817 & ooo $^{\text {b }}$ \\
Total & 799.063 & 58 & 9.984 & & \\
\hline
\end{tabular}

a. Dependent Variable: TOP

b. Predictors: (Constant), TLB, TAT

Sumber: Data primer yang diolah

Hasil uji F menunjukkan bahwa audit tenure dan lowballing berpengaruh terhadap pemberian opini audit. Hal ini dapat dibuktikan dengan tingkat signifikansi o,ooo. Hal ini menunjukkan bahwa audit tenure dan lowballing dihadapkan secara bersama-sama pada pemberian opini audit, maka akan semakin banyak juga pertimbangan yang dilakukan oleh auditor.

Hasil penelitian ini mendukung penelitian yang dilakukan oleh Junaidi dan Hartono (2010) menyebutkan bahwa semakin lama hubungan auditor dengan klien, maka dikhawatirkan semakin rendah pengungkapan atas laporan keuangan perusahaan tersebut. Hal ini akan mempengaruhi pemberian opini audit terhadap perusahaan. Signifikansi pengaruh audit tenure terhadap opini audit yang dikeluarkan oleh perusahaan sejalan dengan Knechel dan Vanstraelen (2007) dan Januarti (2009). Hasil penelitian Lee dan Gu (1998) dan Fatemi (2013) yang membuktikan bahwa lowballing berpengaruh terhadap independensi. Sikap auditor yang tidak independen akan mempengaruhi cara berpikirnya dan menyetujui tindakan klien yang keliru. Pemikiran auditor yang menginginkan terjadinya masa perikatan pada periode selanjutnya, disebabkan auditor memandang klien sebagai sumber pendapatan yang akan berdampak pada pemberian opini yang dilakukan oleh auditor. Dye (1991) dalam Giri (2010) berargumen bahwa lowballing mendorong auditor membuat opini yang memberi keuntungan bagi klien pada awal periode, dan kondisi ini digunakan auditor untuk memperoleh pendapatan dengan harapan klien akan melakukan perikatan audit pada periode selanjutnya.

\section{Koefisien Determinasi}

Koefisien determinasi (Adj $\mathrm{R}^{2}$ ) bertujuan mengukur seberapa jauh kemampuan variabel independen (audit tenure dan lowballing) dalam menjelaskan variasi variabel dependen (pemberian opini audit). Nilai koefisien determinasi adalah antara nol dan satu. Nilai yang mendekati satu berarti variabel independen memberikan hampir semua informasi yang dibutuhkan untuk memprediksi variabel dependen. Adjusted $R$ square digunakan karena banyak peneliti menganjurkan untuk menggunakan ini. Nilai adjusted $R$ square dapat naik atau turun apabila satu variabel independen ditambahkan ke dalam model (Imam Ghozali, 2011:97). 
Tabel 6. Hasil Uji Koefisien Determinasi $\left(R^{2}\right)$ Variabel $X_{1}, X_{2}$ dan $Y$

\begin{tabular}{|l|l|l|l|l|}
\hline Model & $R$ & R Square & Adjusted R Square & $\begin{array}{l}\text { Std. Error of the } \\
\text { Estimate }\end{array}$ \\
\hline 1 & $.521^{\mathrm{a}}$ & .272 & .247 & 3.15972 \\
\hline
\end{tabular}

a. Predictors: (Constant), TAT, TLB

b. Dependent Variable: TOP

Sumber: Data primer yang diolah

Pada tabel 6 menunjukkan variasi audit tenure dan lowballing dapat menjelaskan $24,7 \%$ variasi pemberian opini audit. Sedangkan sisanya $75,3 \%$ dijelaskan oleh variabelvariabel lain di luar model penelitian, seperti independensi (Swari dan Ramantha, 2013) dan lingkungan institusional (Zahra dan Chariri, 2013)

\section{Hasil Regresi Berganda}

Pengujian hipotesis dalam pengujian ini menggunakan multiple regression untuk memprediksi besar variabel dependen dengan menggunakan data variabel independen yang sudah diketahui besarnya (Ghozali, 2011:96).

$$
\mathrm{Y}=13,761+0,158 \mathrm{X}_{1}+0,510 \mathrm{X}_{2}+\varepsilon
$$

Keterangan:

Y = Variabel terikat atau dependen (Pemberian Opini Audit)

$\mathrm{a}=$ Konstanta

$\mathrm{X}_{1}=$ Audit tenure

$\mathrm{X}_{2}=$ Lowballing

$\varepsilon=$ error

\section{SIMPULAN}

Kesimpulan yang dapat diambil dari hasil penelitian ini adalah hasil uji regresi linear berganda menunjukkan bahwa audit tenure tidak berpengaruh secara signifikan terhadap pemberian opini audit. Hal ini dapat dijelaskan oleh besarnya tingkat signifikasi variabel o,o61. Hasil uji regresi berganda menunjukkan bahwa lowballing berpengaruh secara signifikan terhadap pemberian opini audit. Hal ini dapat dijelaskan oleh besarnya tingkat signifikasi variabel o,ooo. Hasil uji regresi linear berganda menunjukkan bahwa audit tenure dan lowballing berpengaruh secara simultan dan positif terhadap pemberian opini audit.

\section{PUSTAKA ACUAN}

Aliya, Angga. Skandal Penipuan Korporasi Terbesar Jepang oleh Olympus. http://finance.detik.com/read/2011/11/o8/153440/1763010/4/skandal-penipuankorporasi-terbesar-jepang-oleh-olympus. Diakses pada tanggal 17 November 2013

Aamir, Suhaib and Umar Farooq, 2011. Auditor-Client Relationship,and Audit Quality;The effects of long-term auditor client relationship on audit quality, in Small and MediumSized Entities (SMEs), ist Edition, LAP Lambert Gmbh \&co.KG, Germany

Agoes Sukrisno. 2012. Auditing (Penunjuk Praktis Pemeriksaan Akuntan oleh Akuntan Publik). Jilid 1, Edisi keempat. Salemba Empat, Jakarta

American Institute of Certified Public Accountants (AICPA). AICPA Professional Standars, Section $A U_{311}$ Planning and Supervision New York, Ny: AICPA. 
Arens, Alvin A, Randal J. Elder, Mark S. Beasley. 2010. Auditing and Assurance Services An Integrated Approach, 13th edition, Pearson Education Inc, Upper Saddle River, New Jersey

Arsianto, Maydica Rossa. 2013. Faktor-faktor yang Mempengaruhi Penerimaan Opini Audit Going Concern. Skripsi, Universitas Diponegoro

Attohiri, Abizar. 2012. Analisis Pengaruh Audit Tenure, Ukuran Perusahaan dan Likuiditas terhadap Opini Audit. Skripsi. Universitas Mataram

Bazerman, M. H., G. F. Loewenstein, and D. A. Moore. 2002. Why god accountants do bad audits, Harvard Business Review 8o(11): 96-102

Boynton, William C, Raymond N. Johnson, Walter G. Kell. 20o6. Modern Auditing: Assurance Services and The Integrity of Financial Reporting. 8th edition, John Wiley\&Sons Inc, United States of America

Dahlan, Ahmad, Pagalung Gagulung dan Tawakkal. 2013. Faktor-faktor yang Mempengaruhi Independensi Auditor. Tesis. Universitas Hasanuddin Makassar

DeAngelo, Linda Elzabeth. 1981. Auditor Independence, 'Low Balling' and Disclosure Regulation, Journal of Accounting and Economics 3, (August)

Deis, D dan Giroux. 1992. Determinants of Audit Quality in the Public Sector, Accounting Review 67(3): pp 62-79

Elitzur, R Ramy and Falk Haim. 1998. Auctions for Services and Low-balling, A Journal of Practice \& Theory Vol. 15

Fatemi, D.J. 2013. New Evidence on an Old Question: Does Lowballing Undermine Auditors' Independence or their Clients' Investment Decisions?, American Accounting Association, Volume 7 Isuues 1

Geiger, M. A, Raghunandan, K. 2002. Auditor Tenure and Audit Reporting Failures, Auditing: A Journal of Practice and Theory 21 (1)

Giri, Ferdinan Efraim. 2010. Pengaruh Tenur Kantor Akuntan Publik (KAP) dan Reputasi KAP terhadap Kualitas Audit: Kasus Rotasi Wajib Auditor di Indonesia”, Simposium Nasional Akuntansi 13

Ghozali Imam, "Aplikasi Analisis Multivariate dengan program IBM SPSS 20”, Cetakan VI, Badan Penerbit Universitas Diponegoro, Semarang, 2009

Ghozali Imam, "Aplikasi Analisis Multivariate dengan program IBM SPSS 20", Cetakan VI, Badan Penerbit Universitas Diponegoro, Semarang, 2011

Hamid, Abdul. 2012. Buku Panduan Penulisan Skripsi. Fakultas Ekonomi dan Bisnis Universitas Islam Syarif Hidayatullah. Jakarta

Hartadi, Bambang. 2012. Pengaruh Fee Audit, Rotasi KAP dan Reputasi Auditor terhadap Kualitas Audit di Bursa Efek Indonesia, Jurnal Ekonomi dan Keuangan Vol. 16, Nomor 1, Yogyakarta

Hobson, L. Jessen, Mark J. Mellon, Douglas E. Stevens. 2011. Could the Winner's Curse Contribute to Low Balling in the Market for Audit Services? Some Experimental Evidence, Department of Accounting at Florida State University

Ikatan Akuntan Indonesia, 2011. Standar Profesional Akuntan Publik, Jakarta, Penerbit Salemba Empat

Irawati, Siti Nur, 2011 "Pengaruh Kompetensi dan Independensi Auditor terhadap Kualitas Audit pada Kantor Akuntan Publik di Makassar", Skripsi Universitas Hasanudin Makassar

Januarti, Indira. 2009. Analisis Pengaruh Faktor Perusahaan, Kualitas Auditor, Kepemilikan Perusahaan Terhadap Penerimaan Opini Audit Going Concern (Perusahaan Manufaktur Yang Terdaftar di Bursa Efek Indonesia). Jurnal Akuntansi, Universitas Dipenogoro, Semarang

Jensen, M.C. and Meckling, W.H. 1976. Theory of The Firm: Managerial Behavior, Agency Cost an Ownership Structure, Journal of Financial Economics, Vol. 3 
Junaidi, dan Jogiyanto Hartono. 2010. Faktor Non Keuangan Pada Opini Going Concern, Simposium Nasional Akuntansi XIII, Purwokerto

Junaidi, Hartono, Suwardi dan Miharjo. 2013. Rotasi Semu dan Tenur KAP pada Independensi, Simposium Nasional Akuntansi XVI, Manado.

Jonasson, G. and Tungel, C. 2012. Occurs Low-balling on the Swedish audit market?. Essay, spring term.

Keputusan Menteri Badan Pengawas pasar Modal dan Lembaga Keuangan Nomor: KEP310/BL/2008 tentang Independensi Akuntan yang Memberikan Jasa di Pasar Modal

Knechel, W. Robert dan Ann Vanstraelen. 2007. The Relationship Between Auditor Tenure and Audit Quality Implied By Going Concern Opinions, Auditing A Journal Of Practice And Theory Vol. 26, No.1, pp 113-131., 2007.

Lee, Chi-Wen Jevons, Gu Zhaoyang. 1998. Low-Balling, Legal Liablility, and Auditor Independence, The Accounting Review; 73

Lennox. 2002. Do Companies Succesfuly Engange in Opinion-shopping? Evidence from the $U K$, Journal of Accounting and Economics 29

Peraturan Menteri Keuangan Nomor 17 Tahun 2008 tentang Jasa Akuntan Publik.

Raharja, Surya. 2007. Independensi: Perjalanan Mencari Titik Temu Antara Profesi dan Bisnis Audit, Akses: Jurnal Ekonomi dan Bisnis Vol. 2 No.3

Rakhmatullah, Tri Subkhi. "Peran Auditor dan Skandal Keuangan Besar", http://m.indonesiafinancetoday.com/read/17774/Peran-Auditor-dan-Skandal-

Keuangan-Besar. Diakses pada tanggal 17 November 2013

Saputri, Inggy Citrasari. 2012. Pengaruh Rotasi Wajib KAP terhadap Hubungan antara Auditor Tenure dan Reputasi KAP dengan Kecenderungan Auditor dalam Menerbitkan Opini Audit Modifikasi Going Concern. Skripsi Universitas Diponogoro

Sari, Kumala dan Rahardja Surya. Analisis Pengaruh Audit Tenure, Reputasi KAP, Disclosure, Ukuran Perusahaan dan Likuiditas terhadap Penerimaan Audit Going Concern (Studi Empiris pada Perusahaan Manufaktur yang Listing di BEI tahun 2005-2010). Artikel

Simmamora, Bilson. 2003. Memenangkan Pasar dengan Pemasaran Efektif dan Profitabel, Cetakan kedua, Gramedia Pustaka Utama

Sinason, D.H., J.P. Jones, dan S.W. Shelton. 2001. An Investigation of Auditor and Client Tenure. Mid-American Journal of Business, Vol. 16, No. 2, pp. 31-40.

Singgih dan Bawono. 2010. Pengaruh Independensi, Pengalaman Pengetahuan, Due Professional Care, dan Akuntabilitas terhadap Kualitas audit, Simposium Nasional Akuntansi XIII, Purwokerto

Suharli, Michell dan Nurlaelah. 2008. Konsentrasi Auditor dan Penetapan Fee Audit: Investigasi pada BUMN, JAAI Vol.12 No.2

Swari, A. Putu Candra Mitha dan Ramantha Wayan. 2013. Pengaruh independensi dan Tiga Kecerdasan terhadap Pertimbangan Pemberian Opini Auditor, E-Jurnal Akuntansi Universitas Udayana 4.3

Zahra, Karina Awalia dan Chariri Anis. 2013. Pengaruh Lingkungan Institusional dan Tipe Auditor terhadap Opini Audit, Diponogoro Journal of Accounting Vol. 2 No.3 